\title{
Reinforcement enhancement by nicotine in adult rats: behavioral selectivity and relation to mode of delivery and blood nicotine levels
}

\author{
Annie Constantin $^{1}$ • Paul B. S. Clarke ${ }^{1}$
}

Received: 17 August 2017 / Accepted: 30 October 2017 / Published online: 11 November 2017

(C) Springer-Verlag GmbH Germany, part of Springer Nature 2017

\begin{abstract}
Rationale Reinforcement-enhancing effects of nicotine occur in human subjects and laboratory rats. However, the doses used in animal studies typically exceed smoking-associated levels of exposure, and generalized behavioral activation by nicotine can potentially confound data interpretation.

Methods During daily 60-min sessions, male adult rats pressed an "active" lever to illuminate a brief cue light. Pressing on either the active or inactive lever retracted both levers for $60 \mathrm{~s}$. Nicotine $(0.025-0.2 \mathrm{mg} / \mathrm{kg})$ was given either by continuous intravenous (IV) infusion, or spaced IV pulses (3-s or 30-s/pulse), or pre-session subcutaneous (SC) injection.

Results Almost all rats responded preferentially for the cue light for several weeks. After several home-cage nicotine injections, reinforcement enhancement occurred even within the first nicotine test session. Nicotine increased active lever responding without altering inactive lever responding, with effects reliably observed at doses as low as $0.1 \mathrm{mg} / \mathrm{kg} \mathrm{SC}$ or $0.1 \mathrm{mg} / \mathrm{kg} / \mathrm{session}$ IV. Within the session, the $0.1 \mathrm{mg} / \mathrm{kg}$ dose maximally increased active lever responding by $2-3$-fold, coinciding with serum levels of $25 \mathrm{ng} / \mathrm{ml}$. Intravenous nicotine (tested at $0.1 \mathrm{mg} / \mathrm{kg} /$ 60-min session) was equally effective whether delivered by continuous infusion or in a series of equally spaced $0.003 \mathrm{mg} / \mathrm{kg}$ pulses each of 3-s or 30-s duration.

Conclusions Low doses of nicotine can potentiate responding for a primary sensory reinforcer without producing a generalized increase in lever pressing. Reinforcer enhancement by
\end{abstract}

Paul B. S. Clarke

paul.clarke@mcgill.ca

1 Department of Pharmacology and Therapeutics, McGill University, McIntyre Medical Building Rm. 1320, 3655 Promenade Sir William Osler, Montreal, Quebec H3G 1Y6, Canada nicotine generalized to several modes of drug delivery, appeared to track circulating levels of drug, and occurred even at serum levels within the daytime range of moderate cigarette smokers.

Keywords Nicotine $\cdot$ Reinforcement enhancement $\cdot$ Route of administration $\cdot$ Pharmacokinetics $\cdot$ Tobacco $\cdot$ Smoking

\section{Introduction}

In the dual-reinforcement model proposed by Caggiula, Donny and co-workers, nicotine promotes tobacco smoking principally via (1) a primary positive reinforcing effect and (2) a reinforcement-enhancing effect, that is, by potentiating the reinforcing effects of smoking-associated cues (Caggiula et al. 2009; Donny et al. 2003). The positive reinforcing effects of nicotine are at best weak, once the drug is isolated from associated sensory cues - as shown both in animals (Caggiula et al. 2002; Chaudhri et al. 2005; Donny et al. 2003; Palmatier et al. 2006; Sorge et al. 2009) and in humans (Duke et al. 2015; Fulton and Barrett 2008; Jensen et al. 2016). In contrast, nicotine can strengthen non-drug reinforcers, both in animal and human subjects (Perkins et al. 2017; Rupprecht et al. 2015).

Tobacco smoking aside, reinforcement enhancement appears critical in maintaining intravenous self-administration (IVSA) of nicotine in animals (Rupprecht et al. 2015). In conventional IVSA procedures, each drug infusion is typically paired with a brief light cue appearing above the lever. Such visual stimuli can serve as weak unconditioned reinforcers (Caggiula et al. 2002; Sorge et al. 2009), and they can also become conditioned reinforcers by association with the drug (Palmatier et al. 2007a); both conditioned and unconditioned reinforcers can be strengthened by nicotine (Rupprecht et al. 2015). 
Reinforcement enhancement by nicotine was initially detected in an intracranial electrical self-stimulation procedure which was specifically designed to avoid the confounding effects of motor output (Clarke and Kumar 1984). However, many subsequent studies have used sensory stimuli (e.g., brief cue light illumination) which serve as either primary reinforcers or conditioned reinforcers; here, response rates on an "active" reinforcer-associated lever are compared with response rates on an "inactive" (control) lever. The rate of inactive lever pressing is intended to control for the potentially confounding effect of general behavioral activation, which is particularly evident after repeated nicotine exposure (Clarke 1987). Currently, the literature appears mixed with regard to behavioral specificity. Thus, nicotine has been reported to increase only active lever responding (Chaudhri et al. 2007; Liu et al. 2007; Olausson et al. 2004a, b; Weaver et al. 2012), or to selectively increase a related operant "observing response" (Raiff and Dallery 2006), but in several other studies, nicotine produced comparable or even larger proportional increases in inactive vs. active lever pressing (Barrett and Bevins 2013; Barrett and Odum 2011; Donny et al. 2003; Grimm et al. 2012; Palmatier et al. 2006; Swalve et al. 2015; Tronci et al. 2010).

Reports of nicotine-induced reinforcement enhancement in animals are based, seemingly without exception, on doses that would provide levels of drug exposure beyond the range typically experienced by tobacco smokers. This issue, documented below, is problematic since to our knowledge no published evidence exists to suggest that rat nicotinic cholinergic receptors are less sensitive than their human counterparts. A cigarette puff delivers approximately $0.001-0.003 \mathrm{mg} / \mathrm{kg}$ of nicotine, with lung-to-brain transit ensuing over many seconds or even minutes (Rose et al. 1999, 2010). In contrast, numerous animal studies have used rapid, high-dose bolus delivery (e.g., $0.03 \mathrm{mg} / \mathrm{kg} /$ infusion, given in $1 \mathrm{~s}$ ) directly via the jugular vein (Caggiula et al. 2009; Chaudhri et al. 2007; Donny et al. 2003; Liu et al. 2007; Palmatier et al. 2007a), with transient concentrations of blood nicotine far exceeding the smoking range (Hieda et al. 1999).

Rapid nicotine spikes of this kind have been avoided in some studies through the use of continuous IV infusion (Donny et al. 2003) or acute SC injection (Barrett and Bevins 2013; Barrett and Odum 2011; Olausson et al. 2004a; Olausson et al. 2004b; Raiff and Dallery 2006; Tronci et al. 2010). However, few if any animal studies have sought to replicate steady-state circulating levels of nicotine that are typical of daily cigarette smokers, i.e., $15-20 \mathrm{ng} / \mathrm{ml}$ (Lawson et al. 1998). The lowest effective doses that have been reported to enhance sensory reinforcers appear to be $0.12 \mathrm{mg} / \mathrm{kg} / \mathrm{h} \mathrm{IV} \mathrm{(Liu} \mathrm{et} \mathrm{al.} \mathrm{2007)} \mathrm{and} 0.175 \mathrm{mg} / \mathrm{kg} \mathrm{SC}$ (Olausson et al. 2004a), and even these relatively low doses would be expected to produce high sustained plasma levels of $20-55 \mathrm{ng} / \mathrm{ml}$ (LeSage et al. 2002; Turner 1975) and 45$100 \mathrm{ng} / \mathrm{ml}$ (Reavill et al. 1990; Turner 1975), respectively.
The present study therefore sought to determine whether nicotine produces unambiguous enhancement of a sensory reinforcer in adult rats exposed to steady-state plasma levels comparable to those found in typical cigarette smokers. Experiment 1 comprised a preliminary investigation of nicotine effects using several different visual reinforcers. Experiment 2 served to compare different nicotine doses, across three modes of administration: intermittent "puff-size" IV infusions, continuous IV infusion, and SC administration. In a final step, minimally effective doses of nicotine were given, in order to measure serum nicotine concentrations.

\section{Methods}

\section{Animals}

Male Long-Evans rats (Charles River, St. Constant, QC, Canada) initially weighed $264-386$ and $248-322 \mathrm{~g}$ (Experiments 1 and 2, respectively). Our decision to use only male rats was based on two considerations: (1) we wished to compare as closely as possible with the published literature, which is largely based on male rats, and (2) there is only mixed evidence for sex differences in nicotine-induced reinforcement enhancement in rats, with both positive (Chaudhri et al. 2005) and negative findings (Barrett et al. 2016; Quick et al. 2014). The rats were housed 2-3 per cage in a temperature- and humidity-controlled animal colony maintained on a reverse 12:12 light/dark cycle, with lights off at $0700 \mathrm{~h}$. Rats were handled for 3-4 days before testing. All behavioral testing took place during the dark phase of the cycle. Food and water were available ad libitum, except during test sessions, which occurred between $0800 \mathrm{~h}$ and $1700 \mathrm{~h}$. Subjects in Experiment 1 had previously taken part in an unrelated study of food reward (chocolate pellet) anticipation; during this earlier study, no drugs were administered and the rats were tested in similar operant cages in which the two levers were permanently retracted. All experimental protocols were approved by the McGill Medical Faculty Animal Care Committee, in accordance with Canadian Council on Animal Care guidelines, in order to minimize pain and discomfort.

\section{Drugs}

Drugs and suppliers were (-)-nicotine hydrogen tartrate salt (Sigma-Aldrich, Oakville, ON), ketamine $\mathrm{HCl}$ (Vetalar ${ }^{\mathrm{TM}}$, Vetrepharm, London, ON), xylazine $\mathrm{HCl}$ (Anased ${ }^{\mathrm{TM}}$, Novopharm, Toronto, ON), and also carprofen (Rimadyl ${ }^{\mathrm{TM}}$ ), enrofloxacin (Baytril ${ }^{\mathrm{TM}}$ ) and propofol (1\% injectable solution, Diprivan $^{\mathrm{TM}}$ ), all from CDMV, St. Hyacinthe, Quebec. Drugs were dissolved in sterile $0.9 \%$ saline as needed. (-)-Nicotine hydrogen tartrate salt solutions were adjusted to $\mathrm{pH} 7.1-7.3$ with $\mathrm{NaOH}$, and stored in aliquots at $-20{ }^{\circ} \mathrm{C}$ until the day of 
use. For IV nicotine administration, a stock solution $(40 \mathrm{mg} / \mathrm{ml})$ was prepared; delivery parameters are described under Experiment 2. Nicotine doses are expressed as the base.

\section{Intravenous catheterization surgery, maintenance and verification of catheter patency}

Rats in Experiment 2 were implanted with IV silastic catheters (ID $0.51 \mathrm{~mm}$ OD $0.94 \mathrm{~mm}$, Fisher Scientific, Montreal, QC) in the right jugular vein, under general anesthesia (ketamine $80 \mathrm{mg} / \mathrm{kg}$ IP and xylazine $16 \mathrm{mg} / \mathrm{kg}$ IP). The catheter was secured to the vein with silk sutures and was passed subcutaneously to the top of the skull where it was connected to a modified cannula (C313G-5UP; PlasticsOne, Roanoke, VA) mounted to the skull with jeweler's screws and dental cement. The analgesic carprofen ( $5 \mathrm{mg} / \mathrm{kg} \mathrm{SC}$ ) was administered during surgery to alleviate post-surgical pain. Immediately postsurgery, catheters were flushed with $0.1 \mathrm{ml}$ of a sterile solution of heparin $(0.2 \mathrm{mg} / \mathrm{ml})$, the antibiotic enrofloxacin $(15 \mathrm{mg} / \mathrm{kg}$, Baytril $^{\mathrm{TM}}$ ), and saline. The cannula was occluded with a plastic stopper (Tygon tubing, Fisher Scientific, Montreal, QC) and shielded with an aluminum cap when not in use. Catheters remained unopened during the 8-day post-surgery recovery period.

From the start of behavioral testing, catheters were flushed on alternating days with $0.1 \mathrm{ml}$ of sterile saline or a solution of heparin $(0.2 \mathrm{mg} / \mathrm{ml})$, enrofloxacin $\left(15 \mathrm{mg} / \mathrm{kg}\right.$, Baytril $\left.{ }^{\mathrm{TM}}\right)$, and saline. In addition, catheter patency was occasionally assessed, where needed, by rapid (3-4 s) IV injection of the general anesthetic propofol $(7 \mathrm{mg} / \mathrm{kg}$, i.e., approx. $0.3 \mathrm{ml}$ of a $1 \%$ solution). This dose produces an immediate loss of righting reflex followed by recovery within 2-3 min.

\section{Behavioral apparatus and testing procedure}

Subjects were tested in operant conditioning chambers (ENV008CT, Med Associates, Lafayette, IN) housed within melamine cubicles. Each box was equipped with two retractable levers (ENV-112CM) located $10 \mathrm{~cm}$ apart and $8 \mathrm{~cm}$ above the stainless steel bar floor. A white cue light $(2.5 \mathrm{~cm}$ diameter, $28 \mathrm{~V}, 100 \mathrm{~mA}, \mathrm{ENV}-221 \mathrm{M}$ ) was situated $3 \mathrm{~cm}$ above each of the two levers. A white house light $(28 \mathrm{~V}, 100 \mathrm{~mA}$, ENV$215 \mathrm{M}$ ) was located on the opposite wall; this was only used in Experiment 1. All visual stimuli were controlled by Med Associates software. For each rat, one lever was designated "active" and the other "inactive". The left-right positions of the active and inactive levers were counterbalanced within each group of subjects. An FR1 schedule of reinforcement was used, with a single response on (only) the active lever producing a visual stimulus. The stimulus comprised either a cue light illuminated above the active lever (both Experiments), or a house light (Experiment 1 only). A response on either lever resulted in the immediate retraction of both levers for a time-out period of
$60 \mathrm{~s}$, after which the levers were again extended into the chamber. Hence, rats could obtain almost 60 visual stimuli per 60 min session at maximum.

Nicotine (or saline) was either injected SC immediately before the test session, or given IV over the course of the test session. Drug was always administered independently of the animals' behavior, i.e., not self-administered. Intravenous solutions were delivered via liquid swivels (rodent swivel model RSP1, Lomir, Notre-Dame-de-L'Ile Perrot, Québec), which were connected to a 3 or $20 \mathrm{ml}$ plastic syringe mounted in a variable rate infusion pump (Med Associates PHM-107). For continuous infusion, the pumps were set to deliver $1.32 \mathrm{ml}$ in $60 \mathrm{~min}$. For intermittent IV delivery, 33 pulses (each of $0.11 \mathrm{ml}, 3-\mathrm{s}$ or $30-\mathrm{s}$ duration) were given at constant intervals of $109 \mathrm{~s}$ throughout the 60-min session, at doses shown in Table 1 . Delivery volumes were confirmed by weighing multiple fluid deliveries with no rat connected.

\section{Serum nicotine assay}

Subjects were profoundly anesthetized with Na pentobarbital (Somnotol) $70 \mathrm{mg} / \mathrm{kg}$ IP, several minutes before sacrifice. Trunk blood was collected after decapitation. Samples were centrifuged at $3000 \mathrm{~g}$ for $10 \mathrm{~min}$ at $4{ }^{\circ} \mathrm{C}$ in order to isolate the

Table 1 Timelines for experiments 1 and 2

\begin{tabular}{|c|c|c|}
\hline Days & Nicotine (mg/kg per session) & Delivery \\
\hline \multicolumn{3}{|c|}{ Experiment 1} \\
\hline $1-4$ & 0 (i.e., saline) & $\mathrm{SC}$ \\
\hline $5-18$ & 0 and 0.1 & $\mathrm{SC}$ \\
\hline \multicolumn{3}{|c|}{ Experiment 2} \\
\hline $1-4$ & 0 (i.e., saline) & $\mathrm{SC}$ \\
\hline $5-8$ & 0 and 0.1 & $\mathrm{SC}$ \\
\hline $9-16$ & $\begin{array}{l}0^{1}, 0.025,0.05,0.1,0.2 \\
0 \text { and } 0.1\end{array}$ & $\begin{array}{l}\text { IV continuous }{ }^{2} \\
\text { SC }\end{array}$ \\
\hline $17-22$ & $\begin{array}{l}0,0.05,0.1,0.2 \\
(0.0015-0.006 / \text { pulse })^{3} \\
0 \text { and } 0.12^{4}\end{array}$ & $\begin{array}{l}\text { IV pulses ( } 33 \text { total, } 30-s \text { ) } \\
\text { IV continuous }\end{array}$ \\
\hline $23-28$ & $\begin{array}{l}0 \text { and } 0.1(0.003 / \text { pulse }) \\
0 \text { and } 0.1(0.003 / \text { pulse }) \\
0 \text { and } 0.1\end{array}$ & $\begin{array}{l}\text { IV pulses ( } 33 \text { total, } 3-\mathrm{s} \text { ) } \\
\text { IV pulses ( } 33 \text { total, } 30-\mathrm{s} \text { ) } \\
\text { IV continuous }\end{array}$ \\
\hline $29-34$ & $0^{1}, 0.025,0.05,0.1,0.2$ & $\mathrm{SC}$ \\
\hline $35-36$ & $\begin{array}{l}0,0.05 \text {, and } 0.1 \\
0,0.05 \text {, and } 0.1\end{array}$ & $\begin{array}{l}\text { SC } \\
\text { IV continuous }\end{array}$ \\
\hline
\end{tabular}

Notes:

1. The saline condition was tested twice in these dose-response blocks 2 . IV continuous delivery refers to constant-rate infusion throughout the 60-min session

3. Nicotine was given as thirty-three 30 -s IV pulses, occurring at constant intervals throughout the session (see Methods). The dose per pulse was varied across sessions

4. Dose miscalculation: the intended dose was 0.10 not $0.12 \mathrm{mg} / \mathrm{kg}$ 
upper transparent serum layer. Serum samples were frozen at $-80^{\circ} \mathrm{C}$ and later assayed for nicotine content in the laboratory of Dr. Paul Pentel (University of Minnesota). This assay is based on gas chromatography with nitrogen-phosphorus detection and has a detection limit of approx. $2 \mathrm{ng}$ per $1 \mathrm{ml}$ sample (Harris et al. 2010).

\section{Experiment 1: repeated nicotine tests with different visual stimuli}

This initial experiment sought to determine (1) whether the visual stimuli were reinforcing, (2) whether nicotine selectively enhanced active lever responding, and (3) whether this effect emerged upon repeated testing. To this end, 29 rats were tested in 18 daily 60-min behavioral sessions (weekends excepted), randomly assigned to four groups. After four saline sessions (i.e., days 1-4), each rat was tested alternately with nicotine $(0.1 \mathrm{mg} / \mathrm{kg} \mathrm{SC})$ and saline (Table 1$)$. The order of drug testing (i.e., NSNS... vs. SNSN...) was counterbalanced across rats. Responding on the active lever resulted in one of four types of visual stimulus, depending on group: 3-s continuous cue light, 3-s flashing cue light, 60-s flashing cue light, and 60-s flashing house light ( $n=7-8$ rats per group). Flashing stimuli were delivered at $5 \mathrm{~Hz}$, in cycles of $0.1 \mathrm{~s}$ on and 0.1 off.

\section{Experiment 2: repeated nicotine tests: dose, mode of delivery, and serum levels}

The purpose was to determine (1) whether nicotine exerts a reinforcement enhancing effect at low doses that provide serum levels typically associated with cigarette smoking, and (2) whether this behavioral effect is altered by pulsatile drug delivery. In this experiment, responding on the active lever illuminated a cue light continuously for $3 \mathrm{~s}$. The findings of Experiment 1 suggested that repeated nicotine exposure might hasten the emergence of a reinforcement enhancing effect; to this end, rats were given home cage once-daily injections of nicotine $(0.1 \mathrm{mg} / \mathrm{kg}$ $\mathrm{SC}$ ) on 4 consecutive days just prior to surgery.

Twenty-nine rats were tested in 34 daily 60 -min behavioral sessions (weekends excepted). The experiment was divided into several testing blocks (Table 1). Days 1-4 comprised saline test sessions, which were followed $1-3 \mathrm{~h}$ later by a home cage injection of nicotine $(0.1 \mathrm{mg} / \mathrm{kg} \mathrm{SC})$. On days 1 and 2 only, for the purpose of habituation, rats were briefly connected to the catheter tubing and then disconnected before injection. Procedural details for each subsequent block are given in Table 1. The order of drug testing was either counterbalanced (days 5-8), randomized (days 9-16), or followed incomplete Williams square designs in order to balance first order carry-over effects (days 17-22, 23-28, 2934). After each testing block, rats were tested for catheter patency as described above.
Finally, rats were sacrificed for blood collection (days 3536). To this end, subjects were randomly allocated to receive nicotine, delivered either SC $(0,0.05$, or $0.1 \mathrm{mg} / \mathrm{kg})$ or by continuous IV infusion $(0,0.05$, or $0.1 \mathrm{mg} / \mathrm{kg} / \mathrm{h})$. Sacrifice was timed to coincide with the maximal behavioral effect of nicotine, i.e., $25 \mathrm{~min}$ after SC injection (see days 29-34) or $50 \mathrm{~min}$ after the start of IV infusion (see days 9-16, 17-22).

\section{Data analysis and statistics}

As detailed above, subjects were assigned to groups and conditions in a randomized or counterbalanced manner. Experimenters were not blind to drug conditions. Commercial software was used for statistical analyses (SYSTAT version 11, SPSS Inc., Chicago, IL, USA). The dependent variables were the number of active and inactive lever presses per 10-min time bin or per 60-min session. The number of reinforcers earned was identical to the number of active presses, and hence was not analyzed. Data were subjected to repeated measures analysis of variance (ANOVA) with one or more of the following within-subject factors: NIC (nicotine vs. saline), DOSE, PULSE (3-s pulses vs. 30-s pulses vs. continuous infusion), DAY (i.e., pairs of sessions in Experiment 1 and individual sessions in Experiment 2), and TIME (time within session). The rates of active and inactive lever responding were not directly compared by ANOVA, because this would have violated the homoscedasticity assumption underlying this test. For repeated measures ANOVA, the Huyhn-Feldt sphericitycorrected $p$ value is reported. The only between-subject factor was STIMULUS (i.e., the four visual stimulus conditions in Experiment 1). Multiple pairwise comparisons were made using paired $t$ tests with $p$ values subjected to the HolmBonferroni adjustment (Ludbrook 1998), referred to here as "H-B paired t-tests". Active vs. inactive lever preference was assessed in each individual rat using a paired $t$ test, with session serving as the experimental unit. The nicotine serum data were subjected to Kitchen's BO test (Kitchen 1987). All $p$ values refer to 2-tailed tests, and $p<0.05$ was considered statistically significant.

\section{Results}

\section{Experiment 1 repeated nicotine tests with different visual stimuli}

The four types of visual stimulus could not be differentiated statistically, either in terms of the STIMULUS main effect or interactions. Results are therefore presented for the pooled groups (i.e., $n=29$ rats; Fig. 1). Preferential responding on the active lever was evident from the first (saline) test onwards. Taking the period of drug testing (days 5-18) as a whole, nicotine increased active lever responses (NIC $F_{1,25}=15.67$, 


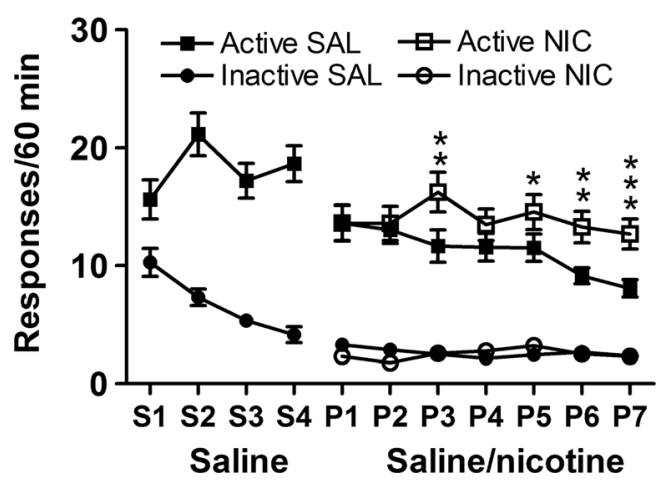

Fig. 1 Experiment 1: Enhancement of active lever pressing by nicotine $(0.1 \mathrm{mg} / \mathrm{kg} \mathrm{SC})$ emerged over days of testing. Four saline tests (S1 to S4) were followed by 7 pairs of alternating saline and nicotine tests (P1 to P7). The $\mathrm{y}$-axis shows the mean \pm SEM active and inactive lever responses per 60-min session ( $n=29$ rats). $* p<0.05, * * p<0.01$, and $* * * p<0.001$, nicotine vs. corresponding saline condition (Holm-Bonferroni adjusted paired $t$ tests)

$p<0.001)$. This stimulant effect was not evident in drug-naïve animals (days 5 and 6) but emerged over successive nicotine and saline tests (i.e., days 5-18: NIC $\mathrm{x}$ linear trend on DAY $F_{1}$, $\left.{ }_{25}=8.90, p<0.01\right)$. Nicotine did not significantly alter inactive lever responses (NIC $F_{1,25}=1.52$, NS) and no stimulant effect on inactive lever responding emerged over successive tests (NIC x linear DAY $F_{1,25}=3.57, \mathrm{NS}$ ).

\section{Experiment 2 repeated nicotine tests: dose, mode of delivery, and serum levels}

General Across the 34 days of the experiment, only 1 of the 29 rats failed to show a significant preference for the active lever (H-B paired $t$ tests, $n=34$ sessions); this rat was therefore excluded from all analyses. The remaining 28 subjects maintained active lever responding throughout the experiment, and the daily group mean varied from about 10 to 20 active lever responses per 1-h session. Inactive lever responses declined over successive days (linear trend on DAY: $F_{1}$, $\left.{ }_{27}=51.65, p<0.0001\right)$. Both active and inactive lever responding declined reliably within individual 60 -min sessions; main effects of TIME (i.e., time within session) are not reported but are illustrated in the figures.

Days 1-4: tests with saline The active lever was preferred on each day, including the first session (active vs. inactive presses, H-B paired $t$ tests: $t_{27}=3.26-5.36, p=0.0030$ 0.0001 ). Pooled across days $1-4$, active and inactive lever responses per session were, respectively, $14.4 \pm 1.0$ and $8.2 \pm 0.6$ (mean \pm SEM, $n=28$ rats).

Days 1-8: initial tests with subcutaneous nicotine Nicotine significantly increased active lever responses (H-B paired $t$ test: $t_{27}=5.48, p<0.0001$ ) but not inactive lever responses $\left(t_{27}=1.80, \mathrm{NS}\right)$. Pooled across days 5-8, active lever responses for saline and nicotine sessions were, respectively, $11.1 \pm 0.8$ and $17.3 \pm 1.4(n=28)$. Corresponding values for inactive lever responses were $4.3 \pm 0.6$ and $5.2 \pm 0.6$. An increase in active lever pressing was evident even upon the first nicotine test (H-B paired $t$ test: $t_{27}=5.55, p<0.0001$ ), presumably reflecting the fact that in this experiment, rats had already received several home-cage nicotine injections.

Days 9-16: continuous intravenous nicotine dose-response Results for days 9-16 are shown in Fig. 2 (panels A, B and C). Intravenous nicotine administration significantly increased active lever responses in a dose- and time-dependent manner $\left(\right.$ DOSE $F_{4,108}=17.50, p<0.0001 ;$ DOSE x TIME $F_{20}$, $540=4.11, p<0.0001)$. Inactive lever responses also appeared affected in a time-dependent way (DOSE $F_{4,108}=3.13$, $p<0.05$; DOSE x TIME $F_{20,540}=1.81, p<0.05$ ). Active lever pressing was stimulated most strongly in the final $20 \mathrm{~min}$ of the session (Fig. 2B), with significant increases at 0.1 and $0.2 \mathrm{mg} / \mathrm{kg}$ (H-B paired $t$ tests: $p<0.0001$ for both). Inactive lever responses also appeared increased at this time (DOSE $F_{4,108}=4.45, p<0.01$ ), with an apparent effect at $0.2 \mathrm{mg} / \mathrm{kg}$ which did not, however, survive correction for multiple comparisons ( $p=0.051$; Fig. 2C).

Subcutaneous administration of nicotine $(0.1 \mathrm{mg} / \mathrm{kg})$ increased active lever responses (Fig. 2A; $F_{1,27}=8.77$, $p<0.01$ ) and this effect appeared time-independent (NIC $\mathrm{x}$ TIME $F_{5,135}=1.02$, NS). The time course of responding (not shown) was similar to that shown on days 29-34 (Fig. 3E below), except that there was no clear effect in the first 10min time bin $\left(t_{27}=1.76, \mathrm{NS}\right)$. Inactive lever responses were not significantly altered by SC nicotine $\left(F_{1,27}=0.17\right.$, NS; Fig. 2A).

Days 17-22: pulsed intravenous nicotine dose-response Results for days 17-22 are shown in Fig. 2 (panels D, E, and F). Nicotine (0, 0.05, 0.1, and $0.2 \mathrm{mg} / \mathrm{kg} / \mathrm{session}$ ), delivered in a series of 30-s IV pulses, increased active lever responses in a dose- and time-dependent manner (DOSE $F_{3}$, $81=31.50, p<0.0001 ;$ DOSE $\times$ TIME $F_{15,405}=3.40$, $p<0.0001)$. Pulsed nicotine also affected inactive lever responses, but in a subtle time-dependent way (DOSE $F_{3}$, $81=2.23$, NS; DOSE x TIME $F_{15,405}=2.22, p<0.05$ ).

For the session as a whole, pulsed nicotine significantly increased active lever responses at 0.1 and $0.2 \mathrm{mg} / \mathrm{kg} / \mathrm{session}$, with no significant effect on inactive lever responses (Fig. 2D). Continuous nicotine infusion (tested only at $0.1 \mathrm{mg} / \mathrm{kg}$ ) also increased active but not inactive lever responses (Fig. 2D). Note: through a miscalculation, the continuous infusion dose was $20 \%$ higher than intended (i.e., $0.12 \mathrm{mg} / \mathrm{kg}$ instead of $0.10 \mathrm{mg} / \mathrm{kg}$ for days $17-22$ ).

Pulsed nicotine appeared to increase active lever responses maximally in the final $20 \mathrm{~min}$ of the session (Fig. 2E), with significant effects again at 0.1 and $0.2 \mathrm{mg} / \mathrm{kg}$ (H-B paired $t$ 
Fig. 2 Experiment 2 (days 9-16 and days 17-22): Continuous and pulsed intravenous nicotine administration both dosedependently increased active lever responding. Left panels (days 9-16): Nicotine was given either as a continuous IV infusion (doses expressed as $\mathrm{mg} / \mathrm{kg}$ per 60min session) or as an acute SC injection $(0.1 \mathrm{mg} / \mathrm{kg})$ immediately pre-session. Right panels (days 17-22): Nicotine was given as a series of 30-s IV pulses, or as a continuous infusion of $0.12 \mathrm{mg} / \mathrm{kg} / \mathrm{session}(20 \%$ higher dose than intended, see Table 1). Each rat was tested under all conditions. Panels A and $\mathrm{D}$ show total-session active and inactive lever responses. Panels $\mathrm{B}, \mathrm{C}, \mathrm{E}$ and $\mathrm{F}$ show the time course of active or inactive lever responses, as indicated; symbols for each of the bottom panels are shown in the overlying panel. For clarity, data relating to $\mathrm{SC}$ administration are omitted from panels B and C. Y-axes show mean $\pm \mathrm{SEM}, n=28$ rats. $* p<0.05$ and $* * * p<0.001$ vs. zero-dose condition (HolmBonferroni adjusted paired $t$ tests)
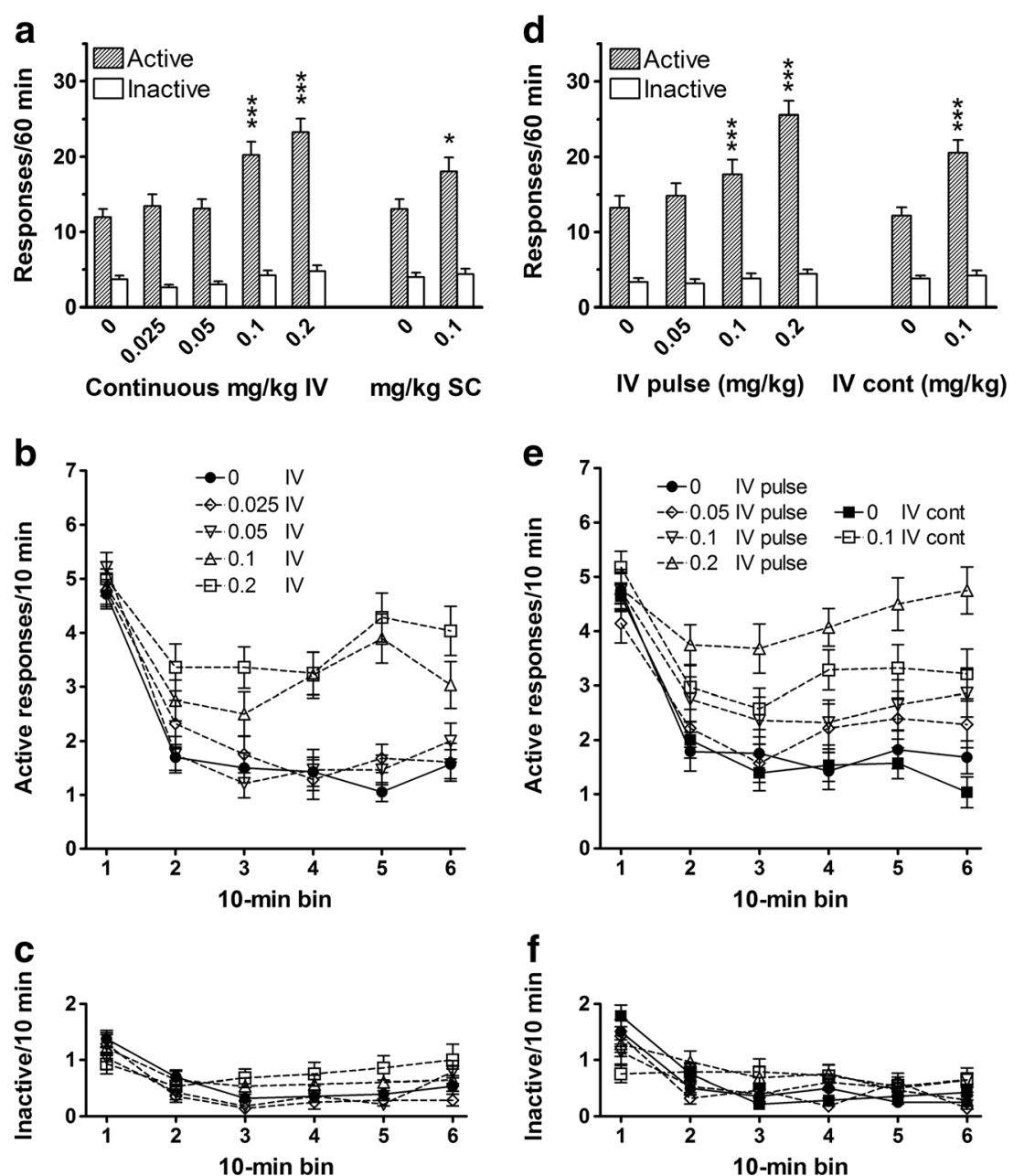

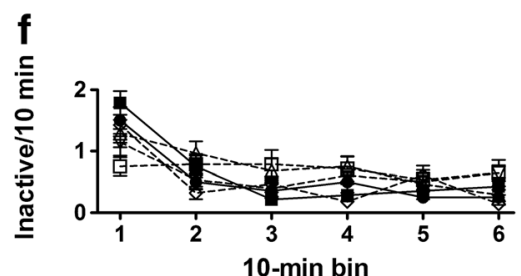

tests: $p<0.001$ and 0.0001 , respectively). Within this time period, mean $\pm \mathrm{SEM}$ active lever responses per $10 \mathrm{~min}$ at 0 , $0.05,0.1$ and $0.2 \mathrm{mg} / \mathrm{kg}$ were respectively $1.8 \pm 0.3,2.3 \pm 0.3$, $2.7 \pm 0.4$ and $4.6 \pm 0.4$. During the same period, inactive lever responses were unaffected (Fig. 2F).

Days 23-28: 3-s vs. 30-s pulses vs. continuous nicotine As shown in Fig. 3A, nicotine increased active lever responses to a comparable extent in the three infusion conditions (NIC $F_{1}$, ${ }_{27}=34.97, p<0.0001 ;$ PULSE $x$ NIC $F_{2,54}=0.055$, NS). The 3-way interaction of PULSE $x$ NIC $x$ TIME was also statistically significant $\left(F_{10,270}=2.43, p<0.05\right)$ but difficult to discern (Fig. 3B). Inactive lever responses (Fig. 3C) were unaffected by nicotine overall (NIC $F_{1,27}=2.30$, NS), but there was a significant NIC $x$ TIME interaction $\left(F_{5,135}=4.23\right.$, $p<0.01)$. In the final $20 \mathrm{~min}$, where stimulation of active lever responses appeared maximal, nicotine did not significantly increase inactive lever responding in any of the three delivery conditions (H-B paired $t$ tests, all NS).

Days 29-34: subcutaneous nicotine dose-response Nicotine increased active lever responses (Fig. 3D: DOSE $F_{4,108}=19.21$, $p<0.0001$ ), with significant effects at 0.1 and $0.2 \mathrm{mg} / \mathrm{kg}$ (Fig. 3E). Inactive lever responses were unaltered (DOSE $F_{4}$, $108=1.01$, NS; Fig. 3F). Active lever responding was increased by nicotine throughout the session (Fig. 3E), but in a timedependent way (DOSE x TIME $F_{20,540}=2.08, p<0.01$ ), such that the maximal effect appeared to occur 10-40 min postinjection (i.e., time bins 2-4). In a post hoc analysis of data collapsed across this time interval, nicotine significantly increased active lever responses at $0.05 \mathrm{mg} / \mathrm{kg}$ as well as at the higher doses (H-B paired $t$ tests: $p<0.05-0.0001$ ).

Days 35-36: serum nicotine levels For a given dose of nicotine, IV and SC administration resulted in closely comparable serum concentrations (sampled at 25 and $50 \mathrm{~min}$ post-injection, respectively, corresponding to the time of maximal behavioral effect). The lower dose of nicotine $(0.05 \mathrm{mg} / \mathrm{kg} \mathrm{IV}$ and SC) provided $11.5 \pm 0.4$ and $12.4 \pm 0.8 \mathrm{ng} / \mathrm{ml}$, respectively, whereas the higher dose $(0.1 \mathrm{mg} / \mathrm{kg}$ IV and SC) provided $23.8 \pm 0.5$ and $26.5 \pm 1.0 \mathrm{ng} / \mathrm{ml}$, respectively (mean $\pm \mathrm{SEM}$, $n=5-6)$. As expected, nicotine was undetectable in serum from the five saline-injected rats. 
Fig. 3 Experiment 2 (days 23-28 and days 29-34): Different types of nicotine pulses produced comparable and selective increases in active lever responding. Left panels (days 23 28): Saline or nicotine $(0.1 \mathrm{mg} / \mathrm{kg}$ per 60-min session) was delivered either as a series of equally spaced short (3-s) or long (30-s) pulses, or by continuous (Cont) infusion (further details in Table 1). Right panels: Panels A and D show active and inactive lever responses occurring during the whole 60-min session. Panels B, $\mathrm{C}, \mathrm{E}$, and $\mathrm{F}$ show the time course of active or inactive lever responses, as indicated; symbols for each of the bottom panels are shown in the overlying panel.

Y-axes show mean \pm SEM, $n=28$ rats. Each rat was tested under all conditions. ${ }^{* * *} p<0.001 v s$. zerodose condition (Holm-Bonferroni adjusted paired $t$ tests)
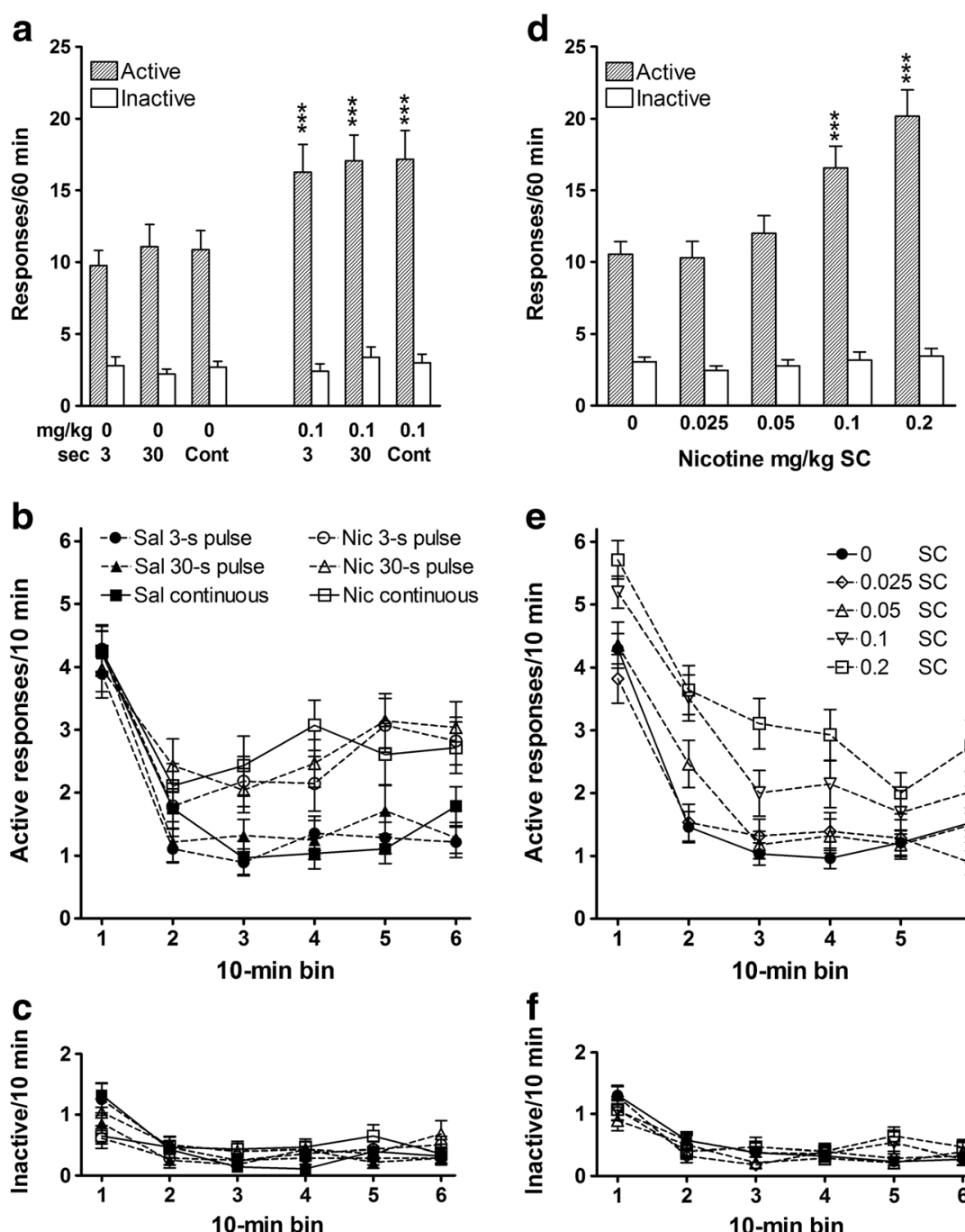

\section{Discussion}

In the present study, acute nicotine administration enhanced the effectiveness of a primary sensory reinforcer in a behaviorally specific manner, over several weeks of testing. We show for the first time that this reinforcement enhancing effect can occur at doses low enough to reproduce steady-state serum nicotine levels typical of habitual cigarette smokers. Furthermore, we show that the temporal pattern of drug delivery was unimportant, in that for a given total dose, subcutaneous injection and continuous drug infusion were both as effective as repeated pulsed delivery. Finally, reinforcement enhancement appeared to track serum nicotine levels across the test session.

\section{Methodological considerations}

Our behavioral procedures differed in several respects from the protocols used by several other groups. First, the operant procedure combined an FR1 schedule with lever retraction during time-out periods. In this way, all active lever presses were reinforced, and no opportunity was provided for response extinction during timeout periods. Second, our rats were neither food-restricted nor trained in advance to leverpress for food, whereas in many previous studies rats have been subjected to chronic food restriction and first trained to respond for food reinforcers with subsequent substitution of a visual stimulus (e.g., Barrett and Odum 2011; Caggiula et al. 2002; Chaudhri et al. 2005; Jones et al. 2010; Palmatier et al. 2006; Swalve et al. 2015; Tronci et al. 2010). Food restriction and training tend to promote responding in the initial lightreinforced sessions (Rupprecht et al. 2015) but potentially complicate data interpretation. Third, the visual stimulus (3-s cue light) used in the main experiment (Experiment 2) was probably less reinforcing than the compound visual stimuli (e.g., light on/house light off) common in previous studies (e.g., Caggiula et al. 2002). Despite these differences, our rats responded preferentially on the active lever from the first test session onwards, and almost all subjects maintained a clear preference for the active lever across the several weeks of 
testing, as previously reported with a stronger visual reinforcer (Weaver et al. 2012).

Our light stimulus could clearly serve as a primary reinforcer, as shown by tests in drug-naïve subjects (Experiment 1). This visual stimulus is unlikely to have acquired significant secondary reinforcer properties through subsequent association with nicotine, for several reasons: (1) within-session nicotine delivery and stimulus presentation were not explicitly paired, but rather occurred independently, (2) nicotine and saline test sessions were equally numerous, and (3) in Experiment 2, additional nicotine injections occurred before any behavioral testing commenced and also after the initial test sessions.

Nicotine's ability to enhance primary sensory reinforcers emerges with repeated drug testing (Palmatier et al. 2007b; Wing and Shoaib 2010). Accordingly, in Experiment 1, a reinforcer-enhancing effect of nicotine emerged only after several test sessions; since these rats were initially drug-naïve, a stimulant effect may have been masked by nicotine's widely reported behavioral depressant effects (for review, see Clarke 1987). Therefore, to avoid this complication, rats in Experiment 2 were first given several home cage injections of nicotine; reinforcer enhancement now occurred even within the first test session. Thus, as previously demonstrated for a conditioned reinforcer (Olausson et al. 2004b), enhancement of the primary visual reinforcer did not require repeated testing under drug.

\section{Behavioral selectivity of nicotine-induced reinforcement enhancement}

In drug-experienced rats, nicotine appears to exert a rather general stimulant effect upon behavior. Thus, nicotine not only reliably increases locomotor activity (Clarke 1987), but can also increase low-rate operant responding (Corrigall et al. 1988), even during timeout periods (Chaudhri et al. 2007; Clarke and Kumar 1983) and on a DRL (differential low rate of reinforcement) schedule (Morrison 1968). The present study therefore examined inactive lever responding in some detail. Since unreinforced response rates tended to be low and somewhat variable, we used large sample sizes ( $n \sim 30$ rats) and repeated measures designs in order to improve statistical power. We tested multiple nicotine doses, routes and delivery parameters, and paid particular attention to conditions where active lever responding was maximally increased by the drug. The present findings, taken together, show that nicotine specifically increased active lever pressing at a dose of $0.1 \mathrm{mg} / \mathrm{kg}$ and possibly lower. Even at the highest dose tested $(0.2 \mathrm{mg} / \mathrm{kg} / \mathrm{session}$ IV or SC), nicotine repeatedly failed to detectably increase inactive lever pressing, with one possible exception (Experiment 2 days 9-16, $p=0.051$ after correction for multiple comparisons). The latter result weakly suggests that high doses of nicotine might be potentially less behaviorally selective than low doses, but against this, there are multiple reports of lever-selective effects at higher doses:
$0.35 \mathrm{mg} / \mathrm{kg}$ SC (Olausson et al. 2004a, b), $0.4 \mathrm{mg} / \mathrm{kg} \mathrm{SC}$ (Weaver et al. 2012), $0.48 \mathrm{mg} / \mathrm{kg} / \mathrm{h}$ IV (Liu et al. 2007), and even $0.99 \mathrm{mg} / \mathrm{kg} / \mathrm{h}$ IV (Chaudhri et al. 2007). Overall, therefore, nicotine dose cannot readily explain why the drug enhanced only active lever responding in some published studies but not in others.

\section{Reinforcement-enhancing effects of nicotine appear to track plasma and brain levels}

To our knowledge, there are no pre-existing studies that directly relate reinforcement enhancement to measured levels of blood nicotine. Our serum levels of nicotine are broadly consistent with literature reports based on SC or IV administration in adult rats (Harris et al. 2010; Pratt et al. 1983; Turner 1975). After SC injection, plasma and brain nicotine levels peak within 5-10 min of injection, and then decline slowly over the next hour (Ghosheh et al. 1999; Hirschhorn and Rosecrans 1974; Pratt et al. 1983; Rollema et al. 2010; Tripathi et al. 1982; Turner 1975). In contrast, our continuous or intermittent IV infusions would be expected to produce steadily increasing nicotine levels across the 1-h session (Guillem et al. 2005; LeSage et al. 2002; Turner 1975). The present behavioral data correspond quite closely to these pharmacokinetic patterns. Thus, when nicotine was given subcutaneously, reinforcement-enhancing effects appeared rapidly and tended to be sustained across the session (Fig. 3E), whereas during IV infusions, the drug effect tended to grow across the 60-min session (Figs. 2B, E, and 3B). Hence, reinforcement enhancement by nicotine appears correlated with the concurrent drug concentration. Another potential explanation for nicotine's behavioral time course would be that nicotine slows habituation to the visual reinforcer, but in a parallel study we were unable to detect such an effect (Wright et al., submitted).

\section{Reinforcement enhancement vs. smoking nicotine levels}

In the present study, reinforcement enhancement became detectable at doses as low as $0.1 \mathrm{mg} / \mathrm{kg} \mathrm{IV}$, and $0.05-0.1 \mathrm{mg} / \mathrm{kg}$ $\mathrm{SC}$, whereas previous attempts to detect effects in this dose range have not shown a convincingly selective effect on active lever responding (Barrett and Odum 2011; Wing and Shoaib 2010). To our knowledge, the minimal doses previously shown to enhance sensory reinforcers were $0.175 \mathrm{mg} / \mathrm{kg} \mathrm{SC}$ (Olausson et al. 2004a) and $0.12 \mathrm{mg} / \mathrm{kg}$ IV (Liu et al. 2007). In Experiment 2, reinforcement enhancement was repeatedly seen at $0.1 \mathrm{mg} / \mathrm{kg}$ (SC and IV), with post hoc analysis suggesting a possible effect even at the lower dose of $0.05 \mathrm{mg} / \mathrm{kg}$ SC. These two doses provided serum nicotine levels of around 12 and $25 \mathrm{ng} / \mathrm{ml}$, respectively, at the time of maximal behavioral effect. This range compares closely to the experience of an average daily smoker, who currently consumes approximately 15 cigarettes per day (Hughes and Callas 2010) and 
achieves trough (i.e., between-cigarette) venous nicotine concentrations of $15-20 \mathrm{ng} / \mathrm{ml}$ (Lawson et al. 1998).

Reinforcement-enhancement by nicotine was obtained not only with rapid bolus IV infusions, but for the first time with "puff-size" nicotine doses each infused over $30 \mathrm{~s}$, hence more closely modeling the kinetics of uptake from the lungs (Rose et al. 1999). Continuous IV infusion appeared at least as effective as pulsatile delivery, consistent with a previous report (Donny et al. 2003). Whether these different modes of nicotine administration all produce reinforcement enhancement via the same neuropharmacological mechanism remains a question for future research.

Rapid bolus delivery of our "puff-size" doses might have proven more effective if infusions had been synchronized with opportunities to lever press. However, cigarette smokers do not experience significant puff-associated nicotine spikes (Rose et al. 1999), and reinforcement enhancement occurs in human subjects even when nicotine is delivered slowly, by lozenge or patch (Barr et al. 2008; Dawkins et al. 2006).

\section{Study strengths and limitations}

Study strengths included methodological simplicity, large sample sizes, and within-experiment replication. Study limitations include the following. First, the rats were given nicotine once daily and hence would have cleared the drug more completely between exposures than in cigarette smokers. Second, only male rats were used; however, a sex difference in nicotine-induced reinforcement enhancement (Chaudhri et al. 2005) has not been found in all studies (Barrett et al. 2016; Quick et al. 2014). Third, the main experiment was lengthy, so that over the course of successive testing blocks, rats were gaining in drug history and behavioral experience. Nevertheless, for a given nicotine dose and mode of delivery, similar-sized effects were observed across testing blocks (compare Figs. 2A, D, and 3A, D).

\section{Conclusion}

The present findings show for the first time that nicotine can produce behaviorally selective enhancement of a sensory reinforcer at levels of drug exposure comparable to those experienced by smokers. The nicotine dosing regimes established here may be of use in mechanistic studies.

\footnotetext{
Acknowledgements The study was supported by a Natural Science and Engineering Research Council of Canada (NSERC) Discovery Grant (155055, to P.B.S.C), and a Canadian Institutes of Health Research of Canada Operating Grant (MOP-10516, to P.B.S.C.). P.B.S.C. is a member of the Center for Studies in Behavioral Neurobiology at Concordia University, Montreal. The authors have no financial relationship with the organizations that sponsored this research. All experiments comply with the current laws of Canada.
}

\section{References}

Barr RS, Pizzagalli DA, Culhane MA, Goff DC, Evins AE (2008) A single dose of nicotine enhances reward responsiveness in nonsmokers: implications for development of dependence. Biol Psychiatry 63:1061-1065

Barrett ST, Bevins RA (2013) Nicotine enhances operant responding for qualitatively distinct reinforcers under maintenance and extinction conditions. Pharmacol Biochem Behav 114-115:9-15

Barrett ST, Odum AL (2011) The effects of repeated exposure on the reward-enhancing effects of nicotine. Behav Pharmacol 22:283-290

Barrett ST, Geary TN, Steiner AN, Bevins RA (2016) Sex differences and the role of dopamine receptors in the reward-enhancing effects of nicotine and bupropion. Psychopharmacology 234:187-198

Caggiula AR, Donny EC, White AR, Chaudhri N, Booth S, Gharib MA, Hoffman A, Perkins KA, Sved AF (2002) Environmental stimuli promote the acquisition of nicotine self-administration in rats. Psychopharmacology 163:230-237

Caggiula AR, Donny EC, Palmatier MI, Liu X, Chaudhri N, Sved AF (2009) The role of nicotine in smoking: a dual-reinforcement model. Neb Symp Motiv 55:91-109

Chaudhri N, Caggiula AR, Donny EC, Booth S, Gharib MA, Craven LA, Allen SS, Sved AF, Perkins KA (2005) Sex differences in the contribution of nicotine and nonpharmacological stimuli to nicotine self-administration in rats. Psychopharmacology 180:258-266

Chaudhri N, Caggiula AR, Donny EC, Booth S, Gharib M, Craven L, Palmatier MI, Liu X, Sved AF (2007) Self-administered and noncontingent nicotine enhance reinforced operant responding in rats: impact of nicotine dose and reinforcement schedule. Psychopharmacology 190:353-362

Clarke PBS (1987) Nicotine and smoking: a perspective from animal studies. Psychopharmacology 92:135-143

Clarke PBS, Kumar R (1983) Nicotine does not improve discrimination of brain stimulation reward by rats. Psychopharmacology 79:271277

Clarke PBS, Kumar R (1984) Effects of nicotine and d-amphetamine on intracranial self-stimulation in a shuttle box test in rats. Psychopharmacology 84:109-114

Corrigall WA, Herling S, Coen KM (1988) Evidence for opioid mechanisms in the behavioral effects of nicotine. Psychopharmacology 96: 29-35

Dawkins L, Powell JH, West R, Powell J, Pickering A (2006) A doubleblind placebo controlled experimental study of nicotine: I- effects on incentive motivation. Psychopharmacology 189:355-367

Donny EC, Chaudhri N, Caggiula AR, Evans-Martin FF, Booth S, Gharib MA, Clements LA, Sved AF (2003) Operant responding for a visual reinforcer in rats is enhanced by noncontingent nicotine: implications for nicotine self-administration and reinforcement. Psychopharmacology 169:68-76

Duke AN, Johnson MW, Reissig CJ, Griffiths RR (2015) Nicotine reinforcement in never-smokers. Psychopharmacology 232:4243-4252

Fulton HG, Barrett SP (2008) A demonstration of intravenous nicotine self-administration in humans? Neuropsychopharmacology 33: 2042-2043

Ghosheh O, Dwoskin LP, Li WK, Crooks PA (1999) Residence times and half-lives of nicotine metabolites in rat brain after acute peripheral administration of [2'-(14)C]nicotine. Drug Metab Dispos 27:14481455

Grimm JW, Ratliff C, North K, Barnes J, Collins S (2012) Nicotine increases sucrose self-administration and seeking in rats. Addict Biol 17:623-633

Guillem K, Vouillac C, Azar MR, Parsons LH, Koob GF, Cador M, Stinus L (2005) Monoamine oxidase inhibition dramatically increases the motivation to self-administer nicotine in rats. $\mathrm{J}$ Neurosci 25:8593-8600 
Harris AC, Mattson C, LeSage MG, Keyler DE, Pentel PR (2010) Comparison of the behavioral effects of cigarette smoke and pure nicotine in rats. Pharmacol Biochem Behav 96:217-227

Hieda Y, Keyler DE, VandeVoort JT, Niedbala RS, Raphael DE, Ross CA, Pentel PR (1999) Immunization of rats reduces nicotine distribution to brain. Psychopharmacology 143:150-157

Hirschhorn ID, Rosecrans JA (1974) Studies on the time course and the effect of cholinergic and adrenergic receptor blockers on the stimulus effect of nicotine. Psychopharmacology 40:109-120

Hughes JR, Callas PW (2010) Data to assess the generalizability of samples from studies of adult smokers. Nicotine Tob Res 12:73-76

Jensen KP, DeVito E, Valentine G, Gueorguieva R, Sofuoglu M (2016) IV nicotine self-administration in smokers: dose-response function and sex differences. Neuropsychopharmacology 41:2034-2040

Jones J, Raiff BR, Dallery J (2010) Nicotine's enhancing effects on responding maintained by conditioned reinforcers are reduced by pretreatment with mecamylamine, but not hexamethonium, in rats. Exp Clin Psychopharmacol 18:350-358

Kitchen I (1987) Statistics in pharmacology: the bloody obvious test. Trends Pharmacol Sci 8:252-253

Lawson GM, Hurt RD, Dale LC, Offord KP, Croghan IT, Schroeder DR, Jiang NS (1998) Application of serum nicotine and plasma cotinine concentrations to assessment of nicotine replacement in light, moderate, and heavy smokers undergoing transdermal therapy. J Clin Pharmacol 38:502-509

LeSage MG, Keyler DE, Shoeman D, Raphael D, Collins G, Pentel PR (2002) Continuous nicotine infusion reduces nicotine selfadministration in rats with 23 -h/day access to nicotine. Pharmacol Biochem Behav 72:279-289

Liu X, Palmatier MI, Caggiula AR, Donny EC, Sved AF (2007) Reinforcement enhancing effect of nicotine and its attenuation by nicotinic antagonists in rats. Psychopharmacology 194:463-473

Ludbrook J (1998) Multiple comparison procedures updated. Clin Exp Pharmacol Physiol 25:1032-1037

Morrison CF (1968) A comparison of the effects of nicotine and amphetamine on DRL performance in the rat. Psychopharmacologia 12: $176-180$

Olausson P, Jentsch JD, Taylor JR (2004a) Nicotine enhances responding with conditioned reinforcement. Psychopharmacology 171:173-178

Olausson P, Jentsch JD, Taylor JR (2004b) Repeated nicotine exposure enhances responding with conditioned reinforcement. Psychopharmacology 173:98-104

Palmatier MI, Evans-Martin FF, Hoffman A, Caggiula AR, Chaudhri N, Donny EC, Liu X, Booth S, Gharib M, Craven L, Sved AF (2006) Dissociating the primary reinforcing and reinforcement-enhancing effects of nicotine using a rat self-administration paradigm with concurrently available drug and environmental reinforcers. Psychopharmacology 184:391-400

Palmatier MI, Liu X, Matteson GL, Donny EC, Caggiula AR, Sved AF (2007a) Conditioned reinforcement in rats established with selfadministered nicotine and enhanced by noncontingent nicotine. Psychopharmacology 195:235-243

Palmatier MI, Matteson GL, Black JJ, Liu X, Caggiula AR, Craven L, Donny EC, Sved AF (2007b) The reinforcement enhancing effects of nicotine depend on the incentive value of non-drug reinforcers and increase with repeated drug injections. Drug Alcohol Depend 89:52-59
Perkins KA, Karelitz JL, Boldry MC (2017) Nicotine acutely enhances reinforcement from nondrug rewards in humans. Front Psychiatry 8 : article 65

Pratt JA, Stolerman IP, Garcha HS, Giardini V, Feyerabend C (1983) Discriminative stimulus properties of nicotine: further evidence for mediation at a cholinergic receptor. Psychopharmacology 81:54-60

Quick SL, Olausson P, Addy NA, Taylor JR (2014) Repeated nicotine exposure during adolescence alters reward-related learning in male and female rats. Behav Brain Res 261:171-176

Raiff BR, Dallery J (2006) Effects of acute and chronic nicotine on responses maintained by primary and conditioned reinforcers in rats. Exp Clin Psychopharmacol 14:296-305

Reavill C, Walther B, Stolerman IP, Testa B (1990) Behavioural and pharmacokinetic studies on nicotine, cytisine and lobeline. Neuropharmacology 29:619-624

Rollema H, Shrikhande A, Ward KM, Tingley FD III, Coe JW, O'Neill BT, Tseng E, Wang EQ, Mather RJ, Hurst RS, Williams KE, de VM, Cremers T, Bertrand S, Bertrand D (2010) Pre-clinical properties of the alpha4beta2 nicotinic acetylcholine receptor partial agonists varenicline, cytisine and dianicline translate to clinical efficacy for nicotine dependence. Br J Pharmacol 160:334-345

Rose JE, Behm FM, Westman EC, Coleman RE (1999) Arterial nicotine kinetics during cigarette smoking and intravenous nicotine administration: implications for addiction. Drug Alcohol Depend 56:99-107

Rose JE, Mukhin AG, Lokitz SJ, Turkington TG, Herskovic J, Behm FM, Garg S, Garg PK (2010) Kinetics of brain nicotine accumulation in dependent and nondependent smokers assessed with PET and cigarettes containing 11C-nicotine. Proc Natl Acad Sci U S A 107:5190 5195

Rupprecht LE, Smith TT, Schassburger RL, Buffalari DM, Sved AF, Donny EC (2015) Behavioral mechanisms underlying nicotine reinforcement. Curr Top Behav Neurosci 24:19-53

Sorge RE, Pierre VJ, Clarke PB (2009) Facilitation of intravenous nicotine self-administration in rats by a motivationally neutral sensory stimulus. Psychopharmacology 207:191-200

Swalve N, Barrett ST, Bevins RA, Li M (2015) Examining the reinforcement-enhancement effects of phencyclidine and its interactions with nicotine on lever-pressing for a visual stimulus. Behav Brain Res 291:253-259

Tripathi HL, Martin BR, Aceto MD (1982) Nicotine-induced antinociception in rats and mice: correlation with nicotine brain levels. J Pharmacol Exp Ther 221:91-96

Tronci V, Vronskaya S, Montgomery N, Mura D, Balfour DJ (2010) The effects of the mGluR5 receptor antagonist 6-methyl-2(phenylethynyl)-pyridine (MPEP) on behavioural responses to nicotine. Psychopharmacology 211:33-42

Turner DM (1975) Influence of route of administration on metabolism of [14C]nicotine in four species. Xenobiotica 5:553-561

Weaver MT, Sweitzer M, Coddington S, Sheppard J, Verdecchia N, Caggiula AR, Sved AF, Donny EC (2012) Precipitated withdrawal from nicotine reduces reinforcing effects of a visual stimulus for rats. Nicotine Tob Res 14:824-832

Wing VC, Shoaib M (2010) A second-order schedule of food reinforcement in rats to examine the role of $\mathrm{CB} 1$ receptors in the reinforcement-enhancing effects of nicotine. Addict Biol 15:380 392 